\title{
RELATION BETWEEN RESILIENCY AND POST-TRAUMATIC GROWTH IN A GROUP OF PARAMEDICS: THE MEDIATING ROLE OF COPING STRATEGIES
}

\author{
NINA OGIŃSKA-BULIK and MAGDALENA KOBYLARCZYK \\ University of Lodz, Łódź, Poland \\ Department of Health Psychology, Institute of Psychology
}

\begin{abstract}
Objectives: The purpose of the research is to investigate the mediating role of coping strategies for stress in the relation between resiliency and post-traumatic growth in a group of paramedics. Material and Methods: Data of 80 paramedics who have experienced traumatic event at their worksites was analyzed. The age range of the participants was 21-67 years old (mean: 35.47, standard deviation: 10.21). The Post-traumatic Growth Inventory, the Assessment Resiliency Scale and Inventory to Measure Coping Strategies for Stress - Mini-Cope were used in the study. Results: Venting of negative emotions and denial appeared as suppressors in analyzing the relation, while planning plays mediating role between resiliency and post-traumatic growth. Conclusions: In the process of post-traumatic growth, both avoidance and problem-focused strategies are important. Moreover, controlling such strategies as Venting and Denial may result in a high level of posttraumatic growth in the study group. The data supports that resiliency may have direct or indirect impact on post-traumatic changes. The results allow to understand the mechanisms of resiliency better, that relationship with post-traumatic growth is ambiguous.
\end{abstract}

Key words:

Coping, Resiliency, Post-traumatic growth, Paramedics, Mediation

\section{INTRODUCTION}

Paramedics are exposed to experiencing traumatic events in the context of their work. They are associated with saving human life and health and the confrontation with death. Studies on members of the emergency rescue team have shown that during fulfilling duties, $72 \%$ of participants experienced a traumatic event at least once and $64 \%$ of them experienced it twice and more [1].

Experiencing traumatic events involves a lot of negative consequences, especially in mental health. Among these consequences post-traumatic stress disorder (PTSD) is mentioned, which is experienced by paramedics in the number from 10-17\% [2]. Studies on traumatic stress conducted in recent years have provided data indicating that experiencing traumatic events may also be associated with the emergence of positive changes after trauma and therefore be a source of transformation, evolution and perception of personal growth. It is known as post-traumatic growth (PTG) phenomenon, which means the occurrence of any positive personal changes, including changes

Received: May 11, 2014. Accepted: November 20, 2014.

Corresponding author: M. Kobylarczyk, University of Lodz, Department of Health Psychology, Institute of Psychology, Smugowa 10/12, 91-433 Łódź, Poland (e-mail: mkobylarczyk@uni.lodz.pl). 
in self-perception, relationships with others and appreciation of life resulting from coping with life crises [3-6]. Changes in self-perception mean perception of emotional growth and may lead to becoming a better person. People reporting such a change describe an increased sense of personal strength, and they feel more experienced in life. Changes in interpersonal relationships reflect people's perceptions of closer and deepening family relations. They describe greater compassion for others, establishing more positive and intimate relationships, an increased appreciation of others, especially close relatives and friends, willingness to express emotions and self-disclose, handling relationships better, acceptance of needing others and knowing that people may be relied upon in times of trouble, better utilisation of social support, and increased confidence in being able to manage relationships.

Changes in philosophy of life reflect positive changes in priorities, the development of greater wisdom, an increased sense of spirituality, and people's increased appreciation for their own life. They describe an increased appreciation for the value of one's own life and of each day, and an improved sense of priority about what is important in life. There is an emergence of new opportunities, the ability and the inclination to make positive life changes, and the development of new interests or paths in life. People reporting this change describe an increased sense of control, intimacy, finding meaning, a better understanding of spiritual matters, and strengthening of religious or spiritual faith [3-5].

Post-traumatic growth is more than just a return to equilibrium after an experienced traumatic event. This phenomenon indicates that the unit, as a result of experienced situations, undergoing some kind of transformation, achieved the trauma level higher than before. The appearance of positive changes after trauma is treated as a result of effective coping with it. This does not exclude the occurrence of the adverse effects of experienced trauma. Post-traumatic growth does not mean that the experience of trauma is desirable or necessary to make significant changes in life. It is not equated with a sense of happiness, either. There is however an opportunity for more meaningful and valuable life [5].

The presence of positive changes after trauma among employees included in the paramedic teams were found in the Australian study [7,8]. In Poland, there have been few research projects on the phenomenon of post-traumatic growth in emergency services. Available data indicates that positive changes after trauma occur in paramedics [9] as well as police officers and firefighters from fire and rescue units [10-12].

Among the many determinants of growth after trauma, the role of coping with stress and personal resources of the individual who has experienced a traumatic event was highlighted. Coping refers to cognitive and behavioral efforts to master, reduce or tolerate the internal and external demands of a stressful encounter. Coping is conceived as a process, by which individuals manage to challenge the threat and demands placed upon them [13]. Coping research has been focused on individual reactions, which are the ways used by the person to cope with problems. Coping strategies are regarded as components of the pathway to PTG [4,14-16].

Strategies such as acceptance, positive reframing, coping focused on the task and based on religion are mentioned as conducive to positive changes after trauma [6,9,17-19]. A particular role for growth after trauma, associated especially with struggling with chronic somatic diseases, is attributed to spiritual/religious coping [20-22] and positive revaluation [23-25]. On the other hand personal resources, conducive to the appearance of positive changes after trauma, include a sense of coherence, self-efficacy, optimism in life, spirituality, and resiliency $[6,10,18]$. Particular importance should be attributed to the resiliency, which may favor the appearance of positive, post-traumatic changes directly or indirectly, determining the choice of more effective strategies for coping with stress. 


\section{The role of resiliency}

\section{in mental development after trauma}

The concept of resilience or resiliency has deep roots in social work. It may be understood as a process (resilience) and as a personality characteristic or resource individuals (resiliency). Concept of resiliency as a personality trait or personality constellation is presented among others by Block and Block [26], Asendorpf and van Aken [27] or by Fredrickson [28].

Resiliency is on the one hand - the individual ability to separate from unpleasant life events, on the other - allowing for more effective coping with stress and negative emotions. It favors perseverance and elastic adaptation to requirements of life, facilitates the mobilization to take remedial action in difficult situations and also increases tolerance of negative emotions and failures. Moreover, individuals being characterized by the higher level of resiliency are more positively predisposed to living and displaying higher selfesteem and self-efficacy. A resilient individual is characterized by emotional stability, more often notices encountered difficulties as the chance of getting new experiences, and is inclined to consider as a person having an impact on making decisions [11,29,30]. Resiliency plays an important role in preventing the negative consequences of negative life events [31,32].

Due to different conceptualisations of the term existing in the literature, i.e. the process (resilience), and the personality characteristics (resiliency), the relationship between resilience/y and PTG is not clear. Some authors equate resilience with post-traumatic growth [33]. Other authors assume that growth is a form of resiliency [34], whereas yet others assume that a benefit from trauma is something more than resilience and therefore plays a superior role [35]. Tedeschi and Calhoun [3] clearly distinguish the 2 concepts of resilience and post-traumatic growth, emphasizing that development following trauma results from transformation, which means cognitive rebuilding.

The relationship between resiliency and growth after trauma were found, among others, in studies of young people experiencing the feeling of horror associated with war, and adults - civilians and soldiers involved in the war in Lebanon [32]. The positive relation between resiliency and post-traumatic growth is also confirmed by Polish research on a group of people who have lost someone close [36,37], in women after mastectomy [38], cardiological patients who experienced cardiological surgery [39], firefighters who have experienced traumatic events in the context of their work [12].

Resiliency can foster the occurrence of post-traumatic positive change directly but also indirectly, determining the choice of a more effective and adapted to the situation, ways of coping with a traumatic event, so one may assume that resiliency treated as personality feature will have an impact on PTG through the mediation of coping strategies.

The purpose of the study was to estimate the mediation role of strategies for coping with stress in the relationship between resiliency and post-traumatic growth in the group of paramedics who have experienced traumatic events in the context of their work.

\section{MATERIAL AND METHODS}

\section{Participants and procedure}

Data of 120 paramedics from the Łódź region, (only men) who have experienced a traumatic event in their worksite were investigated (the research conducted by the seminar participant Joanna Jodłowska). It was conducted during the performance of duties, with the approval of superiors and the consent of the respondents. The aim of the research was explained to the respondents and they were informed of their anonimity. Before completing the questionnaires the respondents answered (in writing) the question whether experienced traumatic events in the course of their duties in the past 5 years (the criterion was adopted to reduce the impact of forgetting; the results of 5 people who have admitted they have experienced more than 1 traumatic event were eliminated). 
Eighty rescuers admitted that such an event took place. The results of this group, which accounted for $66.6 \%$ of all respondents were subject to statistical analysis. The age of participants ranged from 21 to 67 years old $($ mean $(\mathrm{M})=35.47$, standard deviation $(\mathrm{SD})=10.21)$. The split into the younger and older was made on the basis of the mean of age of the respondents. The Post-traumatic Growth Inventory, the Assessment Resiliency Scale and Inventory to Measure Coping Strategies with Stress Mini-Cope were used in the study.

\section{Measures}

The Post-traumatic Growth Inventory (PTGI) developed by Tedeschi and Calhoun [3] is the most frequently used and best-validated questionnaire to assess positive changes after trauma. It consists of 21 items (i.e. "I changed my priorities about what is important in life") rated on a Likert-type scale from 0 ("I did not experience this change as a result of my crisis") to 5 ("I experienced this change to a very great degree as a result of my crisis"). Higher scores indicate higher levels of post-traumatic growth. The Polish adaptation of PTGI [40] comprises of the following 4 factors:

1. Changes in self-perception - as a result of an experienced trauma a person notices new opportunities and perceives growth in personal strength.

2. Changes in relating to others - greater sense of relation to others, increased empathy and altruism.

3. Greater appreciation of life - changes in philosophy of life, a change in priorities, and greater appreciation of everyday life.

4. Spiritual changes - better understanding of spiritual problems and an increase in religiousness. Internal consistency measured by Cronbach's $\alpha$ for the full scale, and test-retest reliability after 2 months are high (0.93, 0.74, respectively).

Inventory Mini-Cope, developed by Carver [41] is a shortened version of the Multidimensional Inventory for
Measuring Coping, known as The Coping Orientations to Problems Experienced (COPE). Polish adaptation of this measurement [42] is a questionnaire that consists of 28 statements allowing for measuring 14 strategies of coping with a difficult situation. They include Active coping, Planning, Positive reframing, Acceptance, Sense of humor, Turning to religion, Seeking emotional support, Seeking instrumental support, Self-distraction, Denial, Venting, Substance use, Behavioral disengagement, and Self-blame. Answers are given according to a 4-point scale, for which the marginal points are used as follows: 0 - "I almost never do it" and 3 - "I almost always do it." The respondents assess the way that they usually cope with stress. The results were calculated as the sum of responses on a particular subscale. The tool has satisfactory psychometric properties (the half reliability $=0.86$ ).

The Resiliency Assessment Scale (SPP-25 - Skala Pomiaru Prężności) by Ogińska-Bulik and Juczyński [30] measures resiliency treated as a personality characteristic which promotes coping with stress. It consists of 25 items (i.e., "I undertake actions to deal with problems no matter how difficult the problems are") rated from 0 (definitively not) to 4 (definitively yes). Factor analysis of the scale revealed 5 factors:

- determination and persistence in actions,

- openness to new experiences and a sense of humor,

- competencies to cope and tolerance of a negative affect,

- tolerance of failures and treating life as a challenge,

- optimistic life attitude and ability to mobilize in difficult situations.

The Resiliency Assessment Scale is a reliable tool: Cronbach's $\alpha=0.89$; internal stability (measured after 4 weeks) $=0.85$.

\section{Statistical analysis}

Mediation analysis was performed based on the procedure of bootstrapping proposed by Preacher and Hayes [43,44], by drawing 5000 bootstrap samples. This method is more 
useful than the quite commonly used Sobel test. It has more explanatory power, it does not require the assumption of normal distribution of variables and allows to conduct analyzes on relatively small samples [44]. Generally, the analysis of mediation allows to set a more complex model structure, in which the independent variable, functioning as a predictor variable (resiliency in this case) is associated with the dependent variable (post-traumatic growth) through a 3rd variable, performing the function of a mediator (coping strategies). Mediating effect, in the form of suppression (enhancement) occurs when the mediating variable increases the predictive properties of the independent variable on the dependent variable.

In a simple mediation model $\mathrm{X}$ represents the independent variable, $\mathrm{Y}$ the dependent measure and $\mathrm{M}$ the intervening or mediating variable. The total effect of $\mathrm{X} \rightarrow \mathrm{Y}$ is represented by the path $\mathrm{c}$, whereas c' represents direct effect of $X \rightarrow Y$. The effect of the independent variable on the mediator is represented by the path a, and the effect of the mediator on the dependent variable, controlling for the independent variable, is represented by the path $b$ (Figure 1). The indirect effect is the product $\mathrm{a} \times \mathrm{b}$, and it is equivalent to $\mathrm{c}-\mathrm{c}^{\prime}$ [45].

According to MacKinnon et al. [46] the mediated effect in the single - mediator model appears when there has

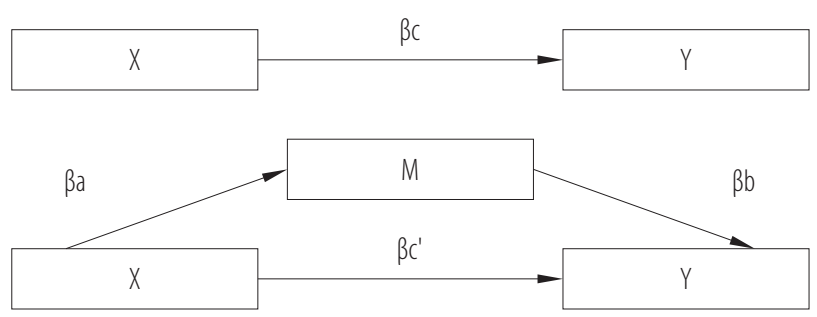

$\mathrm{X}$ - dependent variable; $\mathrm{Y}$ - independent variable; $\mathrm{M}$ - mediator. $\beta c-\beta$ coefficient between dependent and independent variable (total effect); $\beta \mathrm{a}-\beta$ coefficient between dependent variable and mediator (indirect effect); $\beta \mathrm{b}-\beta$ coefficient between mediator and independent variable (indirect effect); $\beta c^{\prime}-\beta$ coefficient between dependent and independent variable (direct effect).

Fig. 1. Simple mediation model been an increase in the value of the coefficient between independent and dependent variable $(c>c)$. Whereas the suppression effect is when there has been a decrease in the $\beta$ coefficient $\left(c^{\prime}>c\right)[47,48]$.

After checking the normality of distribution of analyzed variables (for post-traumatic growth $-\mathrm{d}=0.06, \mathrm{p}>0.2$, skewness $=-0.72$, kurtosis $=0.9$ ), their mean values with standard deviations have been determined (Table 1). In relation to post-traumatic growth, the age of the respondents has been also taken into account. In order to check, which coping strategies are mediators in the relationship resiliency - post-traumatic growth, the mediation analysis have been performed according to the assumptions of Preacher and Hayes [43]. For subsequent analyzes the general results and various factors of resiliency and PTG and all coping strategies were used.

\section{RESULTS}

Having regard to standards developed for The Post-traumatic Growth Inventory (PTGI), they may indicate that 37 rescue workers $(46.2 \%)$ reveal a high, $27(33.8 \%)$ - average and $16(20 \%)$, low levels of post-traumatic growth. Examination was also made in the area of greatest change. For this purpose the mean of the individual factors obtained were divided by the number of the PTGI for their own assertions. Significantly greater changes $(p<0.01)$ refer to the factor 1 - changes in self-perception $(\mathrm{M}=3.43, \mathrm{SD}=0.85)$, and factor 3 - appreciation of life $(\mathrm{M}=3.43, \mathrm{SD}=1.17)$ than a factor of 4 - spiritual changes $(\mathrm{M}=2.55, \mathrm{SD}=1.45)$. Age does not differentiate the severity of post-traumatic positive changes in the examined group of paramedics. Younger (below 36 years): $\mathrm{M}=65.91$ ( $\mathrm{SD}=19.6$ ) did not differ statistically significantly from the older (35 years and more: $\mathrm{M}=72.43(\mathrm{SD}=14.7), \mathrm{t}=-1.61)$ in the overall result of the Post-traumatic Growth Inventory, nor in any of its factors. The average resiliency gained by paramedics does not differ significantly from the average obtained in the study of standardization [26]. The result corresponds to 
Table 1. Post-traumatic growth, resiliency and coping strategies of paramedics

\begin{tabular}{|c|c|c|}
\hline \multirow[t]{2}{*}{ Variable } & \multicolumn{2}{|c|}{$\begin{array}{l}\text { Respondents } \\
\quad(\mathrm{N}=80)\end{array}$} \\
\hline & $\mathrm{M}$ & SD \\
\hline Post-traumatic growth (total) & 68.52 & 17.99 \\
\hline factor 1. Changes in self-perception & 30.87 & 7.66 \\
\hline factor 2. Changes in relations to others & 22.60 & 7.04 \\
\hline factor 3. Appreciation of life & 10.30 & 3.52 \\
\hline factor 4. Spiritual changes & 5.11 & 2.91 \\
\hline Resiliency (total) & 75.17 & 11.48 \\
\hline 1. Determination and persistence in action & 14.70 & 2.82 \\
\hline 2. Openness on new experiences and sense of humour & 15.63 & 2.59 \\
\hline 3. Competencies to cope and tolerance of negative affect & 15.38 & 2.60 \\
\hline 4. Tolerance of failures and treating life as a challenge & 15.01 & 2.76 \\
\hline 5. Optimistic life attitude and ability to mobilize in difficult situations & 14.30 & 2.73 \\
\hline \multicolumn{3}{|l|}{ Coping strategy } \\
\hline Active coping & 4.80 & 3.84 \\
\hline Planning & 4.12 & 1.31 \\
\hline Positive reframing & 3.60 & 1.31 \\
\hline Acceptance & 3.85 & 1.46 \\
\hline Sense of humor & 2.32 & 1.43 \\
\hline Turning to religion & 2.08 & 1.73 \\
\hline Seeking of emotional support & 3.23 & 1.44 \\
\hline Seeking of instrumental support & 3.02 & 1.39 \\
\hline Self-distraction & 3.30 & 1.44 \\
\hline Denial & 1.75 & 1.49 \\
\hline Venting & 2.70 & 1.20 \\
\hline Substance use & 1.55 & 1.61 \\
\hline Behavioral disengagement & 2.70 & 1.20 \\
\hline Self-blame & 2.05 & 1.47 \\
\hline
\end{tabular}

$\mathrm{M}$ - mean; SD - standard deviation.

the 6th Sten and indicates the average level of the variable. Similarly, the average levels of coping strategies are similar to the average means of strategies obtained in the study of standardization [42]. The strategies most commonly used by respondents include Active coping and Planning. The least frequently used are Behavioral disengagement, Substance use and Denial.
Thereafter it was analyzed which of the coping strategies plays the role of mediators in the relationship between resiliency and post-traumatic growth. In the 1st place the relationship between the general result of the resiliency was analyzed and the general result of post-traumatic growth in the group of paramedics and coping strategies were fed as mediators. Fourteen of such analyzes were 
conducted. In the next steps as independent variables factors in resiliency were fed leaving as the dependent variable, the general result of post-traumatic growth. Analyzes with the participation of the dependent variable in the form of individual factors of post-traumatic growth were also carried out, leaving the general result of resiliency as an independent variable.

The results indicated that Venting, expressed in disclosure own negative emotions plays not the mediating, but suppressing role (Figure 2). The introduction of the 3rd variable into the equation as a coping strategy, which is Venting, influences the relationship between resiliency and post-traumatic growth (a slight increase in the value of the $\beta$ coefficient) [38]. Furthermore, the suppressor also affects the significance of the relationship between resiliency and post-traumatic growth. The analysis performed by bootstrapping showed that the indirect effect that had been analyzed is important, since in the range from -0.30 to -0.0063 ( $95 \%$ bias corrected). Controlling such a variable as Venting may cause the appearance of post-traumatic growth to be predicted.

The next step in the analysis of the mediation was to examine which factors of resiliency are predictors of posttraumatic growth and what is the role of coping strategies in these relations. For that purpose, in place of the independent variable subsequent factors of resiliency were introduced. The analyzes suggest that in the case of

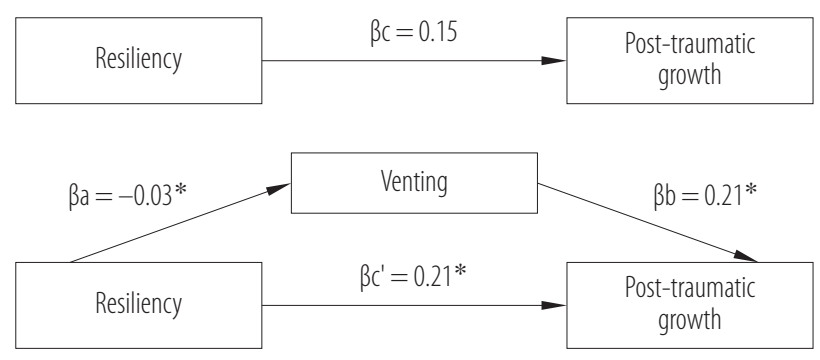

$* \mathrm{p}<0.05$.

Abbreviations as in Figure 1.

Fig. 2. Model of the relations between resiliency, venting and post-traumatic growth the 3rd resiliency factors (Openness on new experiences and sense of humour - the factor 2, Competencies to cope and tolerance of negative effect - the factor 3, and Optimistic life attitude and ability to mobilize in difficult situations - the factor 5) there was an indirect effect (mediation or suppression).

In the relation between Openness on new experiences and sense of humour and post-traumatic growth, 2 coping strategies have proved to be suppressors, such as Denial and Venting (Figure 3 and 4).

The results indicate that the Denial, expressed in rejecting the fact of the experienced situation, increases a direct
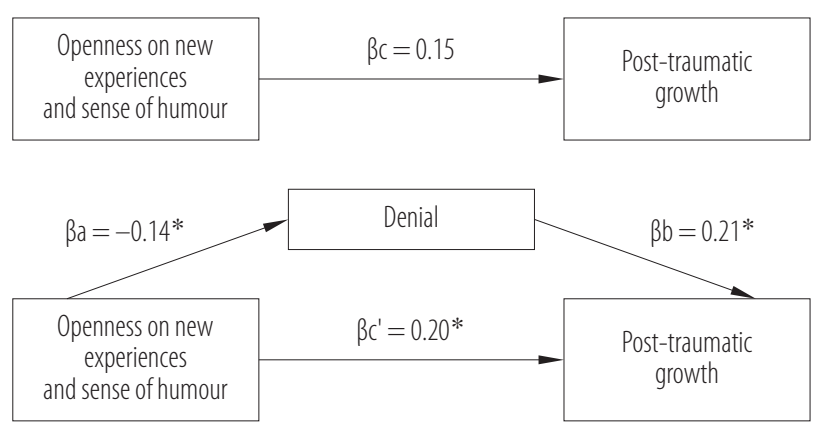

$* \mathrm{p}<0.05$.

Abbreviations as in Figure 1.

Fig. 3. Model of relations between openness on new experiences and sense of humour, denial and post-traumatic growth

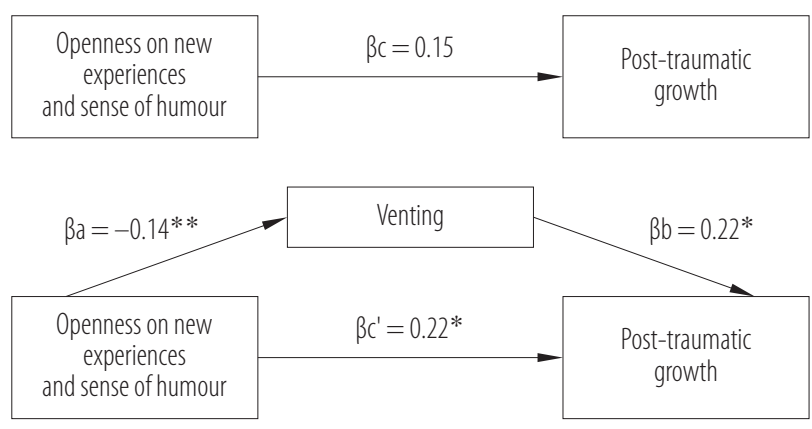

$* \mathrm{p}<0.05$.

$* * \mathrm{p}<0.01$.

Abbreviations as in Figure 1.

Fig. 4. Model of relations between openness on new experiences and sense of humour, venting and post-traumatic growth 
effect of Openness on new experiences and sense of humour on post-traumatic growth (an increase the $\beta$ coefficient).The analyzed indirect effect is within the range from -1.17 to -0.01 ( $95 \%$ bias corrected), and therefore it is important. It should be added that the analyzed factor of resiliency reduces the tendency of the individual to the use of this coping strategy.

A similar role in the relationship between Openness to new experiences and a sense of humor and the post-traumatic growth plays Venting strategy (a slight increase in the value of the $\beta$ coefficient). This relationship became statistically significant (the indirect effect is evaluated to be kept within the range from -1.18 to -0.05 (95\% bias corrected)). The simultaneously examined factor of the resiliency reduces the tendency of the individual to the application of this strategy.

Moreover, controlling the use of coping strategies, as Denial and Venting, causes more predictive power of Openness on new experiences and sense of humour on posttraumatic growth.

In the relationship between Personal competencies to cope and tolerance of negative affect and post-traumatic growth the role of mediator plays Planning strategy (Figure 5).

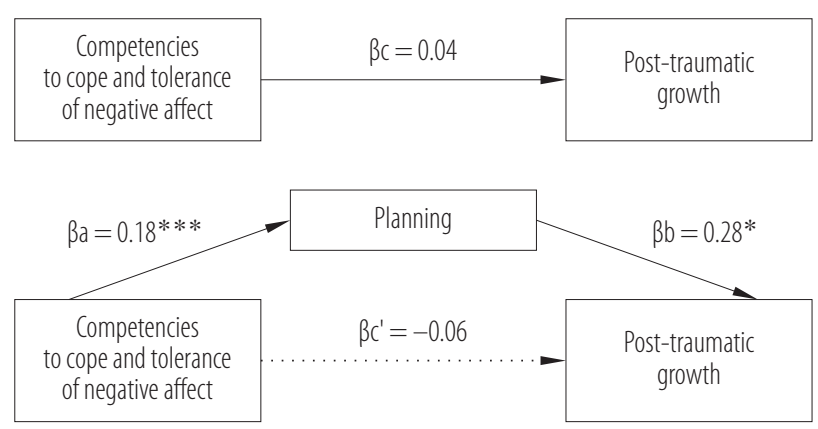

$* \mathrm{p}<0.05$.

$* * * \mathrm{p}<0.001$.

Abbreviations as in Figure 1.

Fig. 5. Model of relations between competencies to cope and tolerance of negative affect, planning and post-traumatic growth
The planning, it is thinking about and planning what should be done, is increasingly the sign of positive, posttraumatic changes (partial mediation), however there still does not have a direct relation between the analyzed factor of the resiliency, and post-traumatic growth (dotted line on Figure 5). However, personal competences in coping are connected with the tolerance of negative emotions, which increases tendencies of applying the Planning strategy.

Planning strategy has also turned out to be the mediator in the relationship between the Optimistic life attitude and the ability to mobilize in difficult situations and posttraumatic growth (dotted line on Figure 6). The Indirect effect is kept within the range of 0.01-1.71, and therefore it is important. The Planning increases the level of growth after trauma; in addition there is still unimportant relationship between the analyzed factor of the resiliency and increasing positive, post-traumatic changes (partial mediation). Optimistic life attitude increases the tendency to use Planning strategy in situations of stress experienced. The final stage of the analysis was to examine the role of coping strategies in the relationship between the general result of the resiliency (independent variable) and

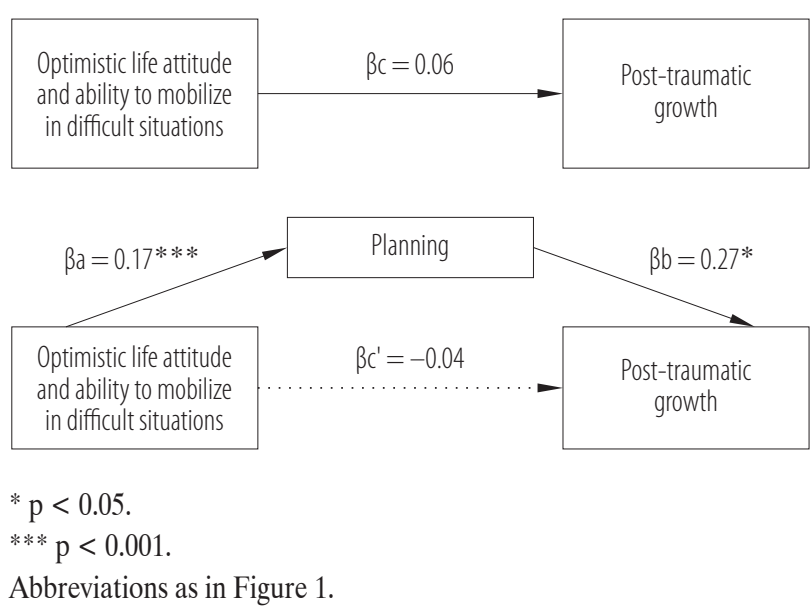

Fig. 6. Model of relations between optimistic life attitude and ability to mobilize in difficult situations, planning and post-traumatic growth 


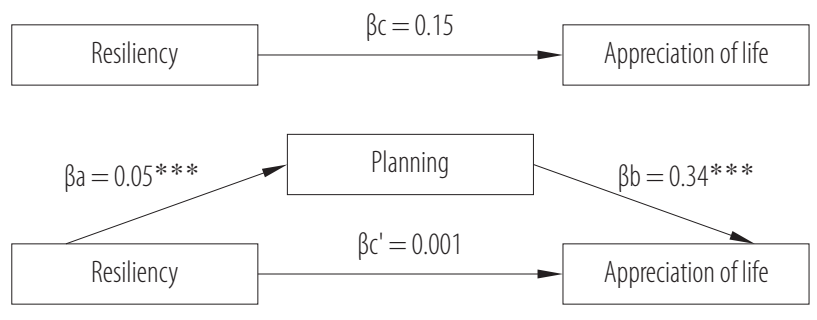

$* * * \mathrm{p}<0.001$.

Abbreviations as in Figure 1.

Fig. 7. Model of relations between resiliency, planning and appreciation of life

the various dimensions of post-traumatic growth (dependent variable). The results of the analysis indicate that the mediator in the relationship resiliency - Appreciation of life turned out to be Planning (Figure 7). The indirect effect in the analyzed model is between 0.01 and 0.10 and is statistically significant (partial mediation). Therefore, a high severity of resiliency leads to a greater Appreciation of life. Resiliency also increases the tendency of respondents to the use of Planning in the process of coping with stress.

On the other hand, the strategy of Denial turned out to be a suppressor in the relationship between resiliency and the occurrence of positive changes in the spiritual realm (Figure 8). An analyzed indirect effect of the variables is significant (from -0.05 to -0.014 ). The control of the use

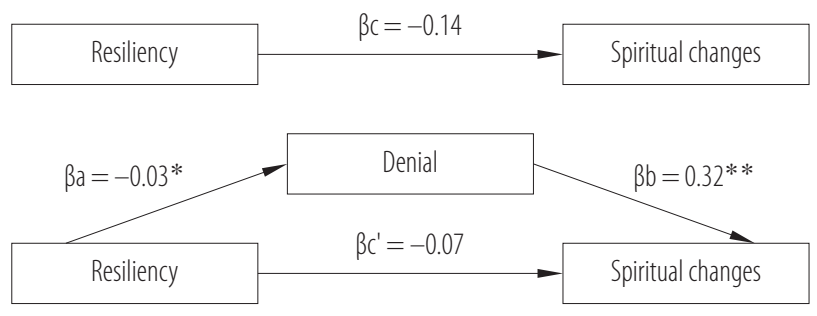

$* \mathrm{p}<0.05$.

$* * \mathrm{p}<0.01$.

Abbreviations as in Figure 1.

Fig. 8. Model of relations between resiliency, denial and spiritual changes of this strategy involves increasing the positive changes in this area of post-traumatic growth. Resiliency reduces the tendency to use Denial of the individual in the process of coping with stress.

\section{DISCUSSION AND CONCLUSIONS}

Nearly $1 / 2$ of the respondent paramedics $(46.2 \%)$ revealed high levels of post-traumatic growth, which can be a result of coping with experienced traumatic events. What is more, the traumatic situations are associated with positive changes. Greater changes related to the Self-perception and Appreciation of life than the Spiritual realm. It should be noted that the observation of positive, post-traumatic changes does not exclude the presence of the respondent negative effects, including symptoms of post-traumatic stress disorder. This is indicated by the results of the Australian researches, conducted among emergency service workers, which showed a positive relationship between negative and positive effects of traumatic experiences [7]. Some of the coping strategies taken by examined paramedics play the role of mediators or suppressors in the relationship between specific dimensions of resiliency and post-traumatic growth. Among them there are both avoidant strategies, such as the Venting of negative emotions, Denial of the situation and a strategy focused on the problem, which is Planning. In general, the use and control of using these strategies promoted positive, posttraumatic changes in the group of the examined paramedics. Particular importance should be attributed to Planning strategy, which aims to consider and analyze the ways to deal with the problem. Its use increases the level of a post-traumatic positive change, especially in terms of Appreciation of life. In addition, the frequent use of this strategy is conditioned by the high intensity of resiliency, especially Competence to cope and Optimistic attitude to life. Generally, the higher resiliency of the respondents revealed, the more they are able to reap the benefits of trauma, by using Planning strategy. 
Positive coping partially mediated the impact of resiliency on PTG in women with infertility [45]. Strategies focused on the problem, which include Planning, proved to be mediators in the relationship between optimism and growth after trauma in women struggling with breast cancer [49]. Strategy Planning served mediating role in the relationship between resiliency and satisfaction with life among persons with diabetes [50].

The results indicate that both strategies of active and avoidance may affect the occurrence of post-traumatic positive changes. The importance of coping strategies, both active and avoidance in the appearance of positive changes after experienced trauma also point to other researchers. The diverse role of coping strategies in the process of growth after trauma has been shown among Australian paramedics. Such strategies as self-help, the approach to solving the problem and accommodation appeared predictors of PTG [7].

A differentiated role of coping strategies in the process of growth after trauma has also been demonstrated in studies of Polish paramedics [9]. The occurrence of growth after trauma (general index) is conducive above all strategies, which are turning to religion, which turn out to be a predictor of positive changes in self-perception, in relationships with others, and spiritual changes. This has corresponded to a large extent with the earlier results, conducted on a group of representatives of the emergency services [10], which provided data indicating the importance of spirituality in the process of appearing post-traumatic positive changes.

The results confirm that the traumatic experience may entail the existence of positive changes, in the form of posttraumatic growth. On the other hand, they indicate a complex picture of the relationship between personality features, used coping strategies and post-traumatic growth. The constraints of the study should be noted. In the group of paramedics the negative effects of experienced traumatic events weren't evaluated. However, the available studies, conducted in Poland as well, indicate the co-existence of positive and negative effects of traumatic experiences, among others, in the victims of road accidents [51], or paramedics [9]. The significance of the type of trauma and the time since the traumatic event has occurred, were not analyzed. It was only assumed that it occurred in the past 5 years. The impact of other socio-demographic factors such as years of education, or socio-economic status not included. The study focuses on the traumatic events associated with the performance of official duties. The consequences of traumatic personal experiences, such as the PTSD, that may occur and affect the level of growth, were not analyzed. The impact of multiple traumas experienced at work at the level of post-traumatic growth was not analyzed, either. The assessment of the positive effects of traumatic events experienced were made using self-report. Therefore the impact of social desirability variable cannot be excluded, i.e., assigning a positive change, even if they did not occur (wishful thinking). The study used a tool to measure the strategies to cope with the stress of different situations (disposition to cope), and not to deal with the trauma suffered. In addition, the study was of crosssectional nature, which does not authorize the inference of causal relationships. From the methodological point of view it would be correct to measure resiliency prior to trauma and to measure coping strategies with experienced event but one should remember that such project is very difficult to conduct.

Despite the constraints obtained, the results bring new content in terms of the consequences incurred in experienced traumatic events. They also allow to understand better the mechanisms of resiliency, that relationship with posttraumatic growth is ambiguous. The data supports that resiliency may have direct or indirect impact on post-traumatic changes. High level of resiliency may assist trauma survivors in adopting official coping strategies, especially Planning, which can promote the PTG. The results may be used in practice, as well as an inspiration for further 
research. Development of resiliency may increase the effectiveness of coping with traumatic experiences. In subsequent studies, it would be worthwhile to consider the role of cognitive engagement, and above all, the importance of rumination. An interesting and significant issue is to check whether the achieved changes persist over time. This would, however, require testing for long-term perspective.

\section{REFERENCES}

1. Dudek B. [Post-traumatic stress disorder]. Gdańsk: GWP; 2003. Polish.

2. Anderson HS, Christensen AK, Peterson GO. Posttraumatic stress reaction among rescue workers after a major rail accident. Anxiety Res. 1991;4:245-51, http://dx.doi.org/ 10.1080/08917779108248778.

3. Tedeschi RG, Calhoun LG. The Post-Traumatic Growth Inventory: Measuring the positive legacy of trauma. J Trauma Stress. 1996;9(3):455-71, http://dx.doi.org/10.1002/jts.2490 090305 .

4. Tedeschi RG, Calhoun LG. Posttraumatic growth: Conceptual foundations and empirical evidence. Psychol Inquiry. 2004;15:1-8, http://dx.doi.org/10.1207/s15327965pli1 501_01.

5. Tedeschi RG, Calhoun LG. [A clinical approach to growth after the experience traumatic]. In: Linley PA, Joseph S, editors. [Positive psychology in practice]. Warszawa: PWN; 2007. p. 230-48. Polish.

6. Ogińska-Bulik N. [The positive effects of traumatic experiences, that is when the tears turn into pearls]. Warszawa: Difin; 2013. Polish.

7. Kirby R, Shakespeare-Finch J, Palk G. Adaptive and maladaptive coping strategies predict posttrauma outcomes in ambulance personnel. Traumatol. 2011;17(4):25-34, http:// dx.doi.org/10.1177/1534765610395623.

8. Shakespeare-Finch JE, Smith SG, Gow KM, Embelton G, Baird L. The prevalence of posttraumatic growth in emergency ambulance personnel. Traumatol. 2003;9(1):58-70, http://dx.doi.org/10.1177/153476560300900104.
9. Ogińska-Bulik N. [The role of coping with stress strategies in posttraumatic growth in medical rescue workers]. Med Pr. 2014;(65)2:209-17, http://dx.doi.org/10.13075/mp. 5893.2014.024. Polish.

10. Ogińska-Bulik N. [Negative and positive effects of traumatic experiences in a group of emergency service workers - The role of personal and social resources]. Med Pr. 2013;64(4):463-72, http://dx.doi.org/10.13075/mp.5893.2013.0048.

11. Ogińska-Bulik N, Juczyński Z. [Personality, stress and health]. Warszawa: Difin; 2010. Polish.

12. Ogińska-Bulik N, Kaflik-Pieróg M. [Occurrence of positive changes in firefighters experiencing job-related traumatic events - The role of resiliency]. Przeds Zarzadz. 2013;14: 193-206. Polish.

13. Lazarus RS, Folkman S. Stress, appraisal, and coping. New York: Springer; 1984.

14. Bussel VA, Naus MJ. A longitudinal investigation of coping and posttraumatic growth in breast cancer survivors. J Psychosoc Oncol. 2010;28:61-78, http://dx.doi.org/ 10.1080/07347330903438958.

15. Zoellner T, Maercker A. Posttraumatic growth in clinical psychology - A critical review and introduction of two component model. Clin Psychol Rev. 2006;26:626-53, http://dx.doi.org/10.1016/j.cpr.2006.01.008.

16. Prati G, Pietrantoni L. Optimism, social support and coping strategies contributing to posttraumatic growth: A metaanalysis. J Loss Trauma. 2009;14(5):364-88, http://dx.doi. org/10.1080/15325020902724271.

17. Helgeson V, Reynolds K, Tomich P. A meta-analytic review of benefit finding and growth. J Consult Clin Psych. 2006; 74(5):797-816, http://dx.doi.org/10.1037/0022-006X.74.5.797.

18. Linley PA, Joseph S. Positive change following trauma and adversity: A review. J Trauma Stress. 2004;17(1):11-21, http://dx.doi.org/10.1023/B:JOTS.0000014671.27856.7e.

19. Shaw A, Joseph SP, Linley A. Religion, spirituality, and posttraumatic growth: A systematic review. Ment Health Relig Cult. 2005;8(1):1-11, http://dx.doi.org/10.1080/13674670320 00157981. 
20. Lelorain S, Tessier P, Florin A, Bonnaud-Antignac A. Posttraumatic growth in long term breast cancer survivors: Relation to coping, social support and cognitive processing. J Health Psychol. 2012;17(5):627-39, http://dx.doi. org/10.1177/1359105311427475.

21. Morris B, Shakespeare-Finch J, Scott J. Coping process and dimensions of posttraumatic growth. Australas J Disaster Trauma Stud. 2007;1:1-12.

22. Thombre A, Sherman AC, Simonton S. Religious coping and posttraumatic growth among family caregivers of cancer patients in India. J Psychosoc Oncol. 2010;28(2): 173-88, http://dx.doi.org/10.1080/07347330903570537.

23. Bellizzi KM, Blank TO. Predicting posttraumatic growth in breast cancer survivors. Health Psychol. 2006;25:47-56, http://dx.doi.org/10.1037/0278-6133.25.1.47.

24. Sears SR, Stanton AL, Danoff-Burg S. The yellow brick road and the emerald city: Benefit finding, positive reappraisal coping, and posttraumatic growth in women with early-stage breast cancer. Health Psychol. 2003;22(5): 487-96, http://dx.doi.org/10.1037/0278-6133.22.5.487.

25. Widows MR, Jacobsen PB, Booth-Jones M, Fields KK. Predictors of posttraumatic growth following bone marrow transplantation for cancer. Health Psychol. 2005;24(3):266-73， http://dx.doi.org/10.1037/0278-6133. 24.3.266.

26. Block JH, Block J. The role of ego-control and ego-resiliency in the origination of behavior. In: Collings WA, editor. The Minnesota Symposia on Child Psychology. Hillsdale (NJ): Erlbaum; 1980. p. 39-101.

27. Asendorpf JB, van Aken MAG. Resilient, overcontrolled, and undercontrolled personality prototypes in childhood: Replicability, predictive power, and the trait-type issue. J Pers Soc Psychol. 1999;77:815-32, http://dx.doi. org/10.1037/0022-3514.77.4.815.

28. Fredrickson B. The role of positive emotions in positive psychology: The broaden-and build theory of positive emotions. Am Psychol. 2001;56:218-26, http://dx.doi. org/10.1037/0003-066X.56.3.218.
29. Semmer N. Personality, stress and coping. In: Vollrath M, editor. Handbook of personality and health. Chichester: Wiley; 2006. p. 73-113, http://dx.doi.org/10.1002/978047071 3860.ch4.

30. Ogińska-Bulik N, Juczyński Z. [The scale measuring resilience - SPP-25]. Nowiny Psychol. 2008;3:39-56. Polish.

31. Connor KM. Assessment of resilience in the aftermath trauma. J Clin Psychiatry. 2006;67(2):46-9.

32. Levine SZ, Laufer A, Stein E, Hamma-Raz Y, Solomon Z. Examining the relationship between resilience and posttraumatic growth. J Trauma Stress. 2009;22(4):282-6, http://dx.doi.org/10.1002/jts.20409.

33. Westphal M, Bonanno GA. Posttraumatic growth and resilience to trauma: Different sides of the same coin or different coins? Appl Psychol. 2007;56:417-27, http://dx.doi. org/10.1111/j.1464-0597.2007.00298.x.

34. Johnson RJ, Hobfoll SE, Hall BJ, Canetti-Nisim D, Galea S, Palmieri PA. Posttraumatic growth: Action and reaction. Appl Psychol. 2007;56:428-36, http://dx.doi. org/10.1111/j.1464-0597.2007.00296.x.

35. Lepore SJ, Revenson TA. Resiliency and posttraumatic growth recovery, resistance and reconfiguration. In: Calhoun LG, Tedeschi RG, editors. Handbook of posttraumatic growth: Research and practice. Mahwah (NJ): Erlbaum; 2006. p. 264-90.

36. Felcyn-Koczewska M, Ogińska-Bulik N. [Psychological factors favoring the occurrence of posttraumatic growth in bereaved people]. In: Ogińska-Bulik N, Miniszewska J, editors. [Health in the human life cycle]. Łódź: Łódź University Press; 2012. p. 59-72. Polish.

37. Ogińska-Bulik N. The relationship between resiliency and posttraumatic growth following death of someone close. Omega-J Death Dying. 2015 [cited 2014 May 5];1:1-12. Available from: http://ome.sagepub.com/content/early/2015/ 03/06/0030222815575502.abstract.

38. Ogińska-Bulik N. [Posttraumatic growth in cancer disease The role of resiliency]. Pol Forum Psychol. 2010;15(2): 125-39. Polish. 
39. Ogińska-Bulik N, Juczyński Z. [Resiliency as a determinant of positive and negative consequences experienced traumatic situation]. Pol Forum Psychol. 2012;17(2):395-410. Polish.

40. Ogińska-Bulik N, Juczyński Z. [Posttraumatic growth-Characteristic and measurement]. Psychiatria. 2010;7(4):129-42. Polish.

41. Carver C. You want to measure coping but your protocol's too long: Consider the brief COPE. Int J Behav Med. 1997;4: 92-100, http://dx.doi.org/10.1207/s15327558ijbm0401_6.

42. Juczyński Z, Ogińska-Bulik N. [Tools for measuring stress and for coping with stress]. Warszawa: PTP; 2009. Polish.

43. Preacher K, Hayes AF. Asymptotic and resampling strategies for assessing and comparing indirect effects in multiple mediator models. Behav Res Methods. 2008;40:879-91, http://dx.doi.org/10.3758/BRM.40.3.879.

44. Cichocka A, Bilewicz M. [What is hidden in nonsignificant effects? Application of suppression analysis in social psychology]. Psychol Spol. 2010;5(14):191-8. Polish.

45. Yu Y, Peng L, Chen L, Long L, He W, Li M, et al. Resilience and social support promote posttraumatic growth of women with infertility: The mediation role of positive coping. Psychiatry Res. 2014;215(2):401-5, http://dx.doi.org/10.1016/ j.psychres.2013.10.032.

46. Rucker DD, Preacher KJ, Tormala ZL, Petty RE. Mediation analysis in social psychology: Current practices and new recommendations. Soc Personal Psychol Compass. 2011;5(6):359-71, http://dx.doi.org/10.1111/j.17519004.2011.00355.x.

47. MacKinnon DP, Fairchild AJ, Fritz MS. Mediation analysis. Ann Rev Psychol. 2007;58:593-614, http://dx.doi.org/ 10.1146/annurev.psych.58.110405.085542.

48. MacKinnon DP, Krull JL, Lockwood CM. Equivalence of the mediation, confounding, and suppression effect. Prev Sci. 2000;1:173-81, http://dx.doi.org/10.1023/A:102659 5011371.

49. Büyükasik-Colak C, Gündogdu-Aktürk E, Bozo O. Mediating role of coping in the dispositional optimism - Posttraumatic growth relation in breast cancer patients. J Psychol. 2012;146(5):471-83, http://dx.doi.org/10.1080/0022398 0.2012.654520.

50. Sęk H, Kaczmarek Ł, Ziarko M, Pietrzykowska E, Lewicka J. [Resiliency and well-being in chronic diseases - Mediating role of empowerment and coping]. Pol Forum Psychol. 2012;17(2):327-43. Polish.

51. Merecz D, Waszkowska M. [Relationships between symptoms of posttraumatic stress and posttraumatic growth among drivers participated in road accidents]. In: Golińska L, Bielawska-Batorowicz E, editors. [Family and work in conditions of crisis]. Łódź: Lódź University Press; 2011. p. 541-52. Polish.

This work is available in Open Access model and licensed under a Creative Commons Attribution-NonCommercial 3.0 Poland License - http://creativecommons.org/ licenses/by-nc/3.0/pl/deed.en. 